\title{
Genetic Stability of Differentiated Functions in Streptomyces hygroscopicus in Relation to Conditions of Continuous Culture
}

\author{
By MARTIN ROTH* AND DIETER NOACK \\ Akademie der Wissenschaften der DDR, Forschungszentrum für Molekularbiologie und \\ Medizin, Zentralinstitut für Mikrobiologie und experimentelle Therapie, Beutenbergstrasse \\ 11, Schliessfach 73, DDR-6900 Jena, German Democratic Republic
}

(Received 19 February 1981; revised 12 May 1981)

\begin{abstract}
The genetic stability of the capacity of an improved strain of Streptomyces hygroscopicus to produce the macrolide antibiotic turimycin was investigated during long-term continuous culture. Dilution rate, growth-limiting substrate and culture temperature were varied. Certain culture conditions resulted in the stable propagation of the inoculated turimycin-producing population. Other conditions led to segregation of the initial population. Turimycin non-producing phenotypes appeared, and in each case the simultaneous loss of ability to form aerial mycelium was observed. The non-differentiating clones were found to be stable, without any reversion to the parental phenotype, indicating that a loss of genetic information probably took place.
\end{abstract}

\section{INTRODUCTION}

An outstanding feature of streptomycetes is the instability or variability of morphological and physiological characters connected with differentiation e.g. the ability to produce antibiotics and pigments, the capacity to form aerial mycelium and spores, and antibiotic resistance. Spontaneous degeneration of different Streptomyces species with respect to their capacity for antibiotic production has been observed upon repeated transfer on solid and in liquid media (Williams \& McCoy, 1953; Perlman et al., 1954; Reusser et al., 1961; Miyoshi et al., 1980), during continuous antibiotic fermentation or chemostat culture (Bartlett \& Gerhardt, 1959; Reusser, 1961; Sala \& Westlake, 1966; Shu, 1966) and during industrial scale manipulations (Miyoshi et al., 1980). In some cases the resulting antibiotic non-producing variants were not able to form aerial mycelium. Spontaneous variants of Streptomyces roseoflavus var. roseofungini lacking aerial mycelium were found during submerged batch culture (Salekh et al., 1978, 1979). The instability of naturally occurring resistance to antibiotics in streptomycetes was reported by Freeman \& Hopwood (1978) and Fedorenko \& Danilenko (1980). The basis for most of the instabilities mentioned seems to be at the genetic level, at least in those cases where no reversion of degenerate variants to the parent phenotype was observed.

Very little is known about factors and conditions influencing the genetic stability of differentiated functions in streptomycetes in spite of the industrial significance of strain degeneration. Therefore, it was the aim of our investigations to establish an experimental method allowing examination of the influence of different culture conditions on the genetic stability of Streptomyces strains. A time-unlimited culture under different constant and reproducible conditions can be realized in the chemostat. For this reason continuous culture 
in a chemostat should be a favourable tool for studying genetic degeneration or segregation processes. In a fundamental study on Streptomyces aureofaciens, Sikyta et al. (1961) showed that under substrate limitation in the chemostat the physiological growth parameters of filamentous streptomycetes are quite similar to those of unicellular micro-organisms (Herbert et al., 1956) provided that the growing mycelium is continuously fractionated.

This paper deals with long-term investigations of the genetic stability of Streptomyces hygroscopicus during continuous culture. The colony-forming units of the chemostat populations were tested for their capacity to produce turimycin, a macrolide antibiotic related to the leucomycin group (Knöll et al., 1971). The results of experiments on the action of acridine orange and ethidium bromide on the antibiotic activity of $S$. hygroscopicus suggested that extrachromosomal DNA might be involved in the regulation of turimycin biosynthesis (Kähler \& Noack, 1974). Thus, it may be that the characteristic growth parameters of chemostat cultures, such as dilution rate (growth rate), growth-limiting substrate and cultivation temperature, influence the genetic stability and stable inheritance of plasmid DNA and consequently the stability of antibiotic production.

\section{METHODS}

Organism. Streptomyces hygroscopicus JA6599/NG60-93 from the collection of the Central Institute of Microbiology and Experimental Therapy, Jena, G.D.R., was used in this study. It is a mutant producing about ten times more turimycin than the wild-type strain S. hygroscopicus JA6599. All experiments were started with spores from lyophilized stocks to obtain a uniform inoculum.

Media. AL53 agar was used for both the propagation of the strain on slants and the plating of samples from chemostat cultures. This contained $\left(\mathrm{g}^{-1}\right)$ : sucrose, 3 ; dextrin, 15; urea, $0 \cdot 1$; yeast extract (Difco), 1; peptone (Difco), $5 ; \mathrm{NaCl}, 0.5 ; \mathrm{KH}_{2} \mathrm{PO}_{4}, 0.5 ; \mathrm{FeSO}_{4}, 0.01 ;$ agar, $15(\mathrm{pH} \mathrm{7.0)}$. Continuous culture was carried out in a mineral salts medium containing $\left(\mathrm{g} \mathrm{l}^{-1}\right): \mathrm{KH}_{2} \mathrm{PO}_{4}, 2 \cdot 72 ; \mathrm{Na}_{2} \mathrm{HPO}_{4} .2 \mathrm{H}_{2} \mathrm{O}, 3.56 ; \mathrm{NaCl}, 5 \cdot 1 ; \mathrm{Na}_{2} \mathrm{SO}_{4}, 1.07$; $\mathrm{MgCl}_{2} .6 \mathrm{H}_{2} \mathrm{O}, 0.041 ; \mathrm{FeCl}_{3}, 0.005 ; \mathrm{MnCl}_{2}, 0.004$; vitamin-free Casamino acids (Difco), $0.1 ; \mathrm{NH}_{4} \mathrm{Cl}, 0.535$ for glucose limitation and 0.08 for $\mathrm{NH}_{4} \mathrm{Cl}$ limitation; glucose, 0.5 for glucose limitation and 2.5 for $\mathrm{NH}_{4} \mathrm{Cl}$ limitation (pH 6.8). Glucose was added to the medium after separate autoclaving for $35 \mathrm{~min}$ at $120^{\circ} \mathrm{C}$.

Preparation of inocula for continuous cultures. Spores from a lyophilized stock were transferred to a slant of AL53 agar. After $8 \mathrm{~d}$ incubation at $28^{\circ} \mathrm{C}$ the spores formed were spread on new slants and spores harvested from these slants were inoculated into $100 \mathrm{ml}$ mineral salts medium $\left(10^{6} \mathrm{ml}^{-1}\right)$. This preculture was grown in a $450 \mathrm{ml}$ Fernbach flask on a reciprocal shaker (frequency 130 strokes $\min ^{-1}$ ) for $15 \mathrm{~h}$ at $28^{\circ} \mathrm{C}$.

Continuous culture in the chemostat. For continuous culture a glass vessel of $250 \mathrm{ml}$ working volume was used. The level of the culture fluid was kept constant by means of an overflow tube. The flow rate of the medium was adjusted by means of a peristaltic pump. The aeration rate was 0.11 air $\mathrm{h}^{-1}$ (ml medium $)^{-1}$. To keep the size of pieces of growing mycelium to a minimum the culture was stirred by a flat glass blade $(15 \times 8 \mathrm{~mm})$ which was fixed horizontally at the end of the stirrer shaft operating at $3000 \mathrm{rev} . \mathrm{min}^{-1}$. The continuous culture vessel was inoculated with $100 \mathrm{ml}$ preculture, and the continuous flow of medium at a low rate $\left(25 \mathrm{ml} \mathrm{h}^{-1}\right)$, aeration and stirring were started immediately. The flow rate was adjusted to the required final rate when the working volume of the culture vessel was reached.

Assay methods for turimycin. In culture filtrates the content of turimycin was determined by an agar diffusion assay method using Bacillus subtilis ATCC 6633 as the test organism. The turimycin production of single colony-forming units from chemostat populations was tested on solid medium by means of a mechanized assay method (Knöll et al., 1981). Samples withdrawn from continuous cultures were diluted and plated on AL53 agar for single colonies. Plates were incubated for $12 \mathrm{~d}$ at $28^{\circ} \mathrm{C}$. From 250 randomly selected colonies per sample, mycelium was transferred by an inoculation apparatus to microculture bowls filled with $1 \mathrm{ml}$ AL53 agar. Incubation was carried out for $6 \mathrm{~d}$ at $28^{\circ} \mathrm{C}$ in special boxes containing 64 microcultures. Thereafter, microcultures were placed on an agar layer to allow diffusion of turimycin through the open bottoms of the microculture bowls. This agar layer was overlaid by soft agar inoculated with Bacillus megaterium TUA1 (Möllmann, unpublished). After $8 \mathrm{~h}$ incubation at $37^{\circ} \mathrm{C}$ the inhibition zones were measured. The percentage of microcultures forming inhibition zones (turimycin-producing) provided a qualitative measure and the mean diameter of these inhibition zones provided a quantitative measure of antibiotic production.

In competition experiments with $\mathrm{Tur}^{+}$and $\mathrm{Tur}^{-}$strains, turimycin production of single colonies (incubated for 6 d) was tested by overlaying with soft agar inoculated with Bacillus megaterium TUA1. Inhibition zones around Tur $^{+}$colonies could be detected after $8 \mathrm{~h}$ incubation at $37^{\circ} \mathrm{C}$. 
RESULTS

\section{Growth of S. hygroscopicus in the chemostat}

The main problem in obtaining a continuous culture of $S$. hygroscopicus was the fractionation of growing mycelium. To obtain a culture suitable for studies of genetic segregation processes, this fractionation had to provide a population of mycelial pieces of minimal size containing a minimal number of chromosomes. High-speed stirring (3000 rev. $\min ^{-1}$ ) by a glass blade stirrer was found to be sufficient for this purpose. In the steady state the resulting continuous culture consisted of small mycelium pellets, each of which contained 20-30 branching tips and had an overall mycelial length of about 100-200 $\mu \mathrm{m}$. The mean numbers of colony-forming units under the different culture conditions are given in Table 1.

The synthetic mineral salts medium for chemostat culture guaranteed unambiguous and reproducible limitation conditions and prevented the formation of turimycin during continuous culture (if turimycin had been present, it could have influenced the genetic segregation processes under study by causing a selection advantage or disadvantage to one genotype). Because of the known inhibitory effect of inorganic phosphate on turimycin production in $S$. hygroscopicus (Gersch et al., 1979), a phosphate buffer system was used as the basis of the mineral salts medium. Only traces of turimycin were detected in filtrates of the continuous culture under both glucose and ammonium chloride limitation, independent of temperature and dilution rate. The maximum specific growth rate of $S$. hygroscopicus NG60-93 in the mineral salts medium was $0.35 \mathrm{~h}^{-1}$, determined by protein measurement (by the Lowry method) in batch culture with high-speed stirring.

\section{Stability of turimycin production in relation to culture conditions in the chemostat}

In each set of experiments two chemostats operating at dilution rates $(D)$ of $0.1 \mathrm{~h}^{-1}$ and $0.3 \mathrm{~h}^{-1}$ with the same medium and at the same temperature were used in parallel. In separate experiments the culture temperature or the growth-limiting substrate of the medium was changed (Table 1). Each experiment was carried out at least twice.

Glucose limitation at $30^{\circ} \mathrm{C}$. Under these conditions at $D=0.3 \mathrm{~h}^{-1}$ (designated culture condition I), turimycin production was stable throughout the culture period of $550 \mathrm{~h}$ (240 generations). Both the percentage of turimycin-producing microcultures and the mean diameter of inhibition zones remained constant at the initial levels (Fig. 1). In contrast, at $D=$ $0.1 \mathrm{~h}^{-1}$ (condition II), a gradual loss of antibiotic production of the colony-forming units of the chemostat population was observed. The mean diameter of inhibition zones of turimycin-producing microcultures characterizing the efficiency of antibiotic production decreased to a minimum value after continuous culture for $480 \mathrm{~h}$ (70 generations) continuous culture (Fig. 1). An increasing number of microcultures appeared which were not able to produce turimycin ( $\left.\mathrm{Tur}^{-}\right)$. Moreover, all these clones also lost the ability to form aerial mycelium and spores $\left(\mathrm{Amy}^{-}\right)$. From a number of such microcultures four successive transfers to fresh AL53 agar were carried out. In some of these clones antibiotic and aerial mycelium formation were restored upon repeated transfers. The other clones were stably Tur $^{-} \mathrm{Amy}^{-}$and did not show any reversion to the parental phenotype $\left(\mathrm{Tur}^{+} \mathrm{Amy}^{+}\right)$, not even after separation of the genomes by protoplast formation and regeneration.

Glucose limitation at $37^{\circ} \mathrm{C}$. During culture for more than $1000 \mathrm{~h}$ (condition III, 432 generations; condition IV, 144 generations) at $37^{\circ} \mathrm{C}$ the chemostat populations were stable with respect to turimycin and aerial mycelium formation, irrespective of the dilution rate. There was no loss of antibiotic activity like that observed at $D=0.1 \mathrm{~h}^{-1}$ and $30^{\circ} \mathrm{C}$ (condition II).

Ammonium chloride limitation at $30^{\circ} \mathrm{C}$. In contrast to the stability of turimycin production under condition I, the population in an ammonium chloride-limited chemostat at $D=0.3 \mathrm{~h}^{-1}$ (condition V) segregated the $\mathrm{Tur}^{+} \mathrm{Amy}^{+}$and $\mathrm{Tur}^{-} \mathrm{Amy}^{-}$phenotypes. However, the segregation kinetics (Fig. 2) differed significantly from that found under condition II (Fig. 
Table 1. Growth conditions for continuous cultures used in the investigation of the genetic stability of turimycin production by $S$. hygroscopicus

$\begin{array}{cccccc}\begin{array}{c}\text { Culture } \\ \text { condition }\end{array} & \begin{array}{c}\text { Growth- } \\ \text { limiting } \\ \text { substrate }\end{array} & \begin{array}{c}\text { Temperature } \\ \left({ }^{\circ} \mathrm{C}\right)\end{array} & \begin{array}{c}\text { Dilution } \\ \text { rate, } D \\ \left(\mathrm{~h}^{-1}\right)\end{array} & \begin{array}{c}\text { No. of } \\ \text { colony-forming } \\ \text { units } \mathrm{ml}^{-1}\end{array} & \begin{array}{c}\text { Genetic } \\ \text { segregation }\end{array} \\ \text { I } & \text { Glucose } & 30 & 0.3 & 1.5 \times 10^{6} & \text { None } \\ \text { II } & \text { Glucose } & 30 & 0.1 & 2.5 \times 10^{6} & \text { Observed } \\ \text { III } & \text { Glucose } & 37 & 0.3 & 3.1 \times 10^{6} & \text { None } \\ \text { IV } & \text { Glucose } & 37 & 0 \cdot 1 & 3.7 \times 10^{6} & \text { None } \\ \text { V } & \mathrm{NH}_{4} \mathrm{Cl} & 30 & 0.3 & 1.0 \times 10^{6} & \text { Observed } \\ \text { VI } & \mathrm{NH}_{4} \mathrm{Cl} & 30 & 0.1 & 2.0 \times 10^{6} & \text { None }\end{array}$

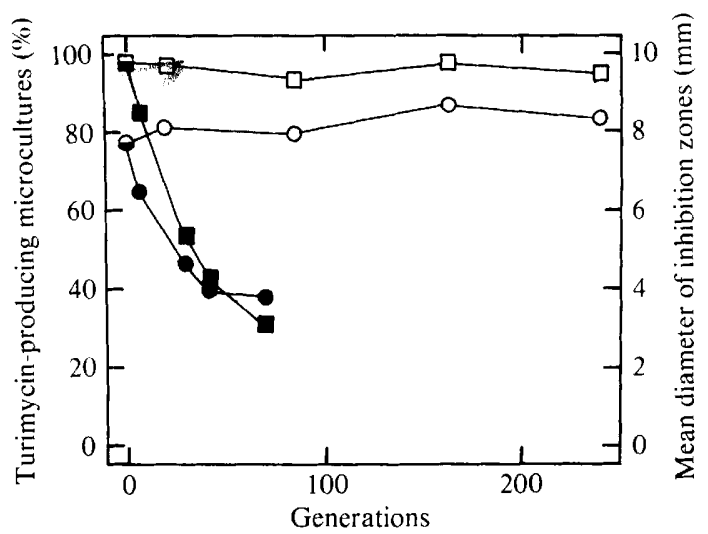

Fig. 1, Dependence of turimycin production by $S$. hygroscopicus NG60-93 on culture time in the chemostat with glucose limitation at $30^{\circ} \mathrm{C}$. Samples from continuous cultures were spread on AL53 agar medium. From the colonies obtained about 250 per sample were randomly selected and transferred to microculture bowls filled with AL53 agar. Turimycin production by microcultures was tested quantitatively (mean diameter of measurable inhibition zones; $O, O$ ) and qualitatively (percentage of turimycin-producing microcultures; $\square, \square$ ) by a bioassay. Open symbols, $D=0.3 \mathrm{~h}^{-1}$; filled symbols, $D=0.1 \mathrm{~h}^{-1}$.

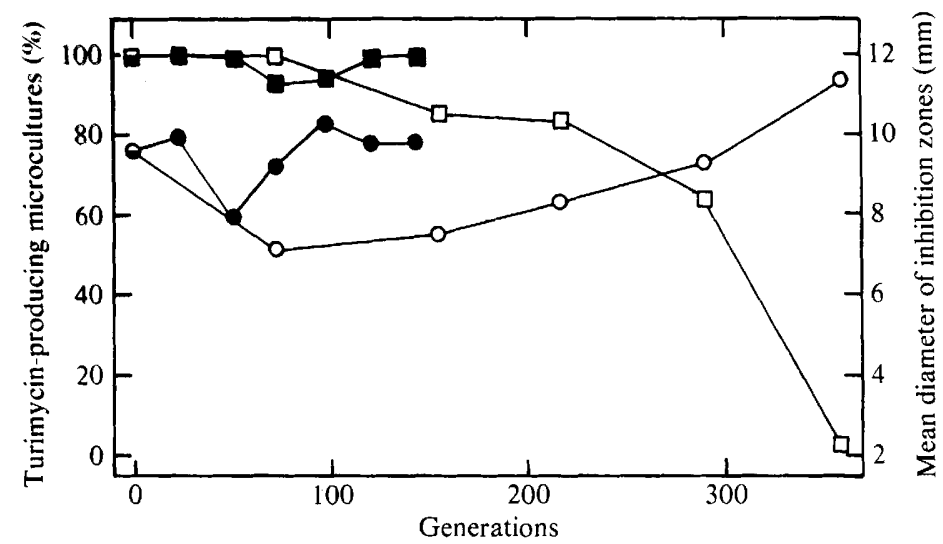

Fig. 2. Dependence of turimycin production by $S$. hygroscopicus NG60-93 on culture time in the chemostat with ammonium chloride limitation at $30^{\circ} \mathrm{C}$. Details and symbols as in Fig. 1. 


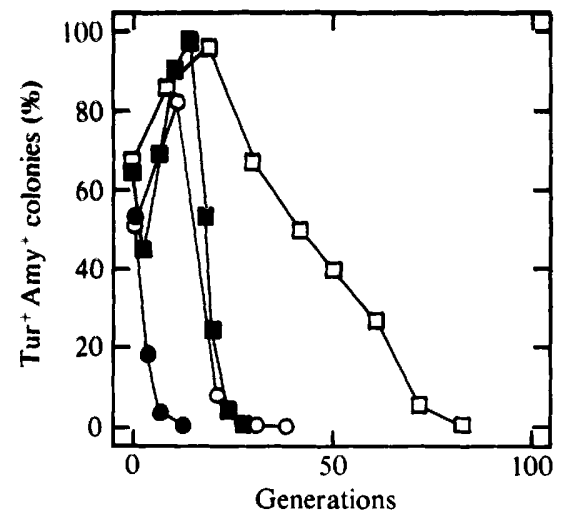

Fig. 3. Competition between the $\mathrm{Tur}^{+} \mathrm{Amy}^{+}$strain S. hygroscopicus NG60-93 and the Tur ${ }^{-} \mathrm{Amy}^{-}$ derivative $C C 1$ in continuous cultures with glucose $(O, O)$ and ammonium chloride limitation $(\square, \square)$ at $30^{\circ} \mathrm{C}$. The proportions of $\mathrm{Tur}^{+} \mathrm{Amy}^{+}$colony-forming units were determined by plating samples from the continuous cultures. Open symbols, $D=0.3 \mathrm{~h}^{-1}$; filled symbols, $D=0.1 \mathrm{~h}^{-1}$.

1). After about 200 h (86 generations) a few Tur $^{-}$Amy $^{-}$colony-forming units appeared, and during further culture the proportion of those with the $\mathrm{Tur}^{+}$phenotype gradually decreased to $5 \%$ after $840 \mathrm{~h}$ (364 generations). However, the remaining turimycin-producing colonyforming units of the chemostat population were not altered with respect to the efficiency of antibiotic production based on the mean diameter of inhibition zones. Stable Tur $^{-} \mathrm{Amy}^{-}$ clones showing no reversion to the parental $\mathrm{Tur}^{+} \mathrm{Amy}^{+}$phenotype were isolated.

At $D=0.1 \mathrm{~h}^{-1}$ (condition VI), segregation into different phenotypes was not observed. Turimycin production was unchanged during continuous culture for $984 \mathrm{~h}$ (142 generations) (Fig. 2).

\section{Competition experiments with Tur $^{+}$and Tur ${ }^{-}$strains}

To obtain more information for interpretation of the segregation kinetics, competition experiments were carried out. About half the volume of a continuous culture of the $\mathrm{Tur}^{+} \mathrm{Amy}^{+}$strain NG60-93 was replaced by a culture of the Tur $^{-}$Amy $^{-}$derivative CC1 (isolated in an experiment under condition II) grown under the same conditions in a chemostat. Samples from the mixed chemostat populations were plated on AL53 agar to determine the proportion of $\mathrm{Tur}^{+} \mathrm{Amy}^{+}$colony-forming units (Fig. 3). The parental strain NG60-93 was outgrown by the non-differentiating derivative CC1 under all conditions tested. With glucose limitation at $D=0.1 \mathrm{~h}^{-1}$ a particularly rapid decrease of the $\mathrm{Tur}^{+} \mathrm{Amy}^{+}$ colony-forming units within the population was observed. Under conditions I, V and VI the proportion of $\mathrm{Tur}^{+} \mathrm{Amy}^{+}$colonies decreased only after an initial increase.

These results indicate that an automatic enrichment of $\mathrm{Tur}^{+}$phenotypes within a heterogeneous population cannot be expected, not even with conditions I and VI, which were found to be suitable for maintaining a homogeneous $\mathrm{Tur}^{+} \mathrm{Amy}^{+}$population.

\section{DISCUSSION}

Our results show that the stability of turimycin production by $S$. hygroscopicus during continuous culture depends on the growth rate, growth-limiting substrate and temperature. On the one hand, it is possible to obtain reproducible culture conditions resulting in the propagation of a homogeneous $\mathrm{Tur}^{+} \mathrm{Amy}^{+}$population without strain degeneration. On the other hand, there are some culture conditions which lead to segregation of the initial strain into two different phenotypes. 
The appearance of $\mathrm{Tur}^{-} \mathrm{Amy}^{-}$phenotypes in our test procedure indicates that changes took place at the genetic level. This is further supported by the stability of the $\mathrm{Tur}^{-} \mathrm{Amy}^{-}$ clones. It can be assumed that in those cases where the $\mathrm{Tur}^{+} \mathrm{Amy}^{+}$phenotype was restored during repeated transfers on solid medium the mycelial colony-forming units from the chemostat were genetically inhomogeneous.

There are two possible explanations for the changes in genotype - either spontaneous mutation(s) in genes responsible for antibiotic biosynthesis or irreversible loss of genetic information. Our experimental results support the latter. First, spontaneous mutations are in general point mutations. Mutation and back-mutation occur at comparable frequencies. However, revertants from $\mathrm{Tur}^{-} \mathrm{Amy}^{-}$clones were never found. Secondly, the copy-error hypothesis of mutation predicts that the mutation rate should be proportional to the rate of gene replication, and consequently to the growth rate. Experimental results concerning spontaneous and caffeine-induced mutations in continuous culture supported this hypothesis (Kubitschek \& Bendigkeit, 1961, 1964). However, our experiments with glucose limitation at $30^{\circ} \mathrm{C}$ (Fig. 1) showed the opposite result: at low dilution rate $\left(D=0 \cdot 1 \mathrm{~h}^{-1}\right) \mathrm{Tur}^{-} \mathrm{Amy}^{-}$ phenotypes appeared, but a high dilution rate $\left(D=0.3 \mathrm{~h}^{-1}\right)$ this segregation was not observed. Thirdly, the loss of turimycin production was associated in each case with loss of the ability to form aerial mycelium. Spontaneous mutations in structural or regulatory genes involved in antibiotic biosynthesis should not cause the simultaneous loss of aerial mycelium formation.

Considering earlier findings (Kähler \& Noack, 1974) we suppose that the loss of genetic information responsible for differentiation might be caused by curing of extrachromosomal DNA. However, definite identification and physical characterization of this hypothetical plasmid DNA has not yet been possible due to insufficient reproducibility of banding in $\mathrm{CsCl}$-ethidium bromide gradient centrifugation (Zippel, unpublished). Several authors have suggested the involvement of plasmids in genetic and metabolic processes in streptomycetes (see Hopwood, 1978; Akagawa et al., 1979), but evidence by physical characterization of plasmid DNA has been obtained in only a few cases (Kirby \& Hopwood, 1977; Okanishi \& Umezawa, 1978; Yagisawa et al., 1978; Akagawa et al., 1979; Hayakawa et al., 1979; Omura et al., 1979). Besides plasmid loss, the deletion of chromosomal DNA as a consequence of transposition of transposons or IS elements might also have caused the appearance of non-differentiating derivatives.

The kinetics of segregation of $S$. hygroscopicus into different genotypes observed during continuous culture (conditions II and V) could result from two processes: (i) the appearance of Tur $^{-}$Amy $^{-}$clones by loss of genetic information (segregation) and (ii) subsequent enrichment of the non-differentiating phenotype due to a selection advantage caused by altered growth parameters such as substrate saturation constants and yield coefficients. From the competition experiments at $30^{\circ} \mathrm{C}$ (Fig. 3), we conclude that $\mathrm{Tur}^{-}$clones appearing in an originally homogeneous $\mathrm{Tur}^{+}$population should outgrow the $\mathrm{Tur}^{+}$strain. Therefore, stability of turimycin production (conditions I and VI) reflects a lack of genetic segregation. Limitation of energy source (condition II; Fig. 1) seems to cause a continuous 'wash-out' of genetic information from the growing mycelium, as indicated by the gradual decrease in turimycin production of the $\mathrm{Tur}^{+}$phenotypes (measured as the mean diameter of inhibition zones). This might be interpreted on the basis of the supposed plasmid loss by reduced effectiveness of plasmid replication because of limitation of precursors for DNA synthesis. However, in the second case of genetic segregation (condition V; Fig. 2) the remaining Tur ${ }^{+}$ colony-forming units were not impaired in turimycin production. Consequently, general loss of genetic information did not occur.

An increase in temperature (conditions III and IV) seems to promote genetic stability with respect to differentiation in $S$. hygroscopicus. A similar effect on degeneration of the bicyclomycin-producing $S$. sapporonensis was reported by Miyoshi et al. (1980).

In our studies we observed lower numbers of colony-forming units at $D=0.3 \mathrm{~h}^{-1}$ than at 
$D=0 \cdot 1 \mathrm{~h}^{-1}$ (Table 1). This can be attributed to the smaller diameter of hyphae at the lower dilution rate (Riesenberg \& Bergter, 1979) leading to an increased response to shear forces. Alterations of mycelial morphology dependent upon the limiting substrate and dilution rate of a continuous culture (Riesenberg \& Bergter, 1979) could influence genetic segregation processes as well as the outcome of competition between $\mathrm{Tur}^{+}$and $\mathrm{Tur}^{-}$phenotypes.

We conclude that continuous culture is a useful tool for studying genetic stability and segregation in relation to differentiation in Streptomyces. It was possible to isolate non-differentiating variants under suitable conditions in the chemostat without application of mutagens or plasmid-curing dyes which could cause mutations in, for example, structural genes of antibiotic biosynthesis. The availability of such variants permits genetic, physiological and biochemical investigation of the regulation of differentiation processes. In addition, the possibility of maintaining a genetically homogeneous population with respect to antibiotic production under defined conditions in the chemostat might be useful to the microbial technologist confronted with degeneration of industrial strains of Streptomyces.

The authors wish to thank Karin Gaube and H.-J. Menz for their excellent technical assistance. We are also indebted to Dr Gertraud Bradler and her colleagues for providing the Streptomyces and Bacillus strains and for technical support.

\section{REFERENCES}

akagawa, H., Okanishi, M. \& Umezawa, H. (1979). Genetics and biochemical studies of chloramphenicol-nonproducing mutants of Streptomyces venezuelae carrying plasmid. Journal of Antibiotics 32, 610-620.

Bartlett, M. C. \& Gerhardt, P. (1959). Continuous antibiotic fermentation. Design of a 20 litre, singlestage pilot plant and trials with two contrasting processes. Journal of Biochemical and Microbiological Technology and Engineering 1, 359-377.

Fedorenko, V. A. \& Danilenko, V. N. (1980). Instability of natural multiple drug resistance in actinomycetes. Antibiotiki 25, 170-174. (in Russian)

Freeman, R. F. \& Hopwood, D. A. (1978). Unstable naturally occurring resistance to antibiotics in streptomycetes. Journal of General Microbiology 106, 377-381.

Gersch, D., SKurK, A. \& Römer, W. (1979). Phosphate inhibition of secondary metabolism in Streptomyces hygroscopicus and its reversal by cyclic AMP. Archives of Microbiology 121, 91-96.

Hayakawa, T., Tanaka, T., Sakaguchi, K., Otake, N. \& Yonehara, H. (1979). A linear plasmid-like DNA in Streptomyces sp. producing lankacidin group antibiotics. Journal of General and Applied Microbiology 25, 255-260.

Herbert, D., Elsworth, R. \& Telling, R. C. (1956). The continuous culture of bacteria: a theoretical and experimental study. Journal of General Microbiology 14, 601-622.

Hopwood, D. A. (1978). Extrachromosomally determined antibiotic production. Annual Review of Microbiology 32, 373-392.

KÄHLER, R. \& NoACK, D. (1974). Action of acridine orange and ethidium bromide on growth and antibiotic activity of Streptomyces hygroscopicus JA6599. Zeitschrift für allgemeine Mikrobiologie 14, 529--533.
Kirby, R. \& HoPwOOD, D. A. (1977). Genetic determination of methylenomycin synthesis by the SCP1 plasmid of Streptomyces coelicolor A3(2). Journal of General Microbiology 98, 239-252.

KNöll, H., Bradler, G., Fügner, R., Kramer, P., Prauser, H., Forberg, W., Strumpf, E., Fricke, H., EFFEnBERger, W. \& Thrum, H. (1971). Verfahren zur Gewinnung eines Makrolidantibiotikums. DDR Patent 84450.

KNöll, H., Bradler, G., Schicht, G. \& Forberg, W. (1981). Das Autoselect-System - ein Automatensystem zur Selektion von Antibiotikaproduzenten. I. Methodische Grundlagen. Acta biotechnologica 1, 63-70.

KubitscheK, H. E. \& Bendigkeit, H. E. (1961). Latent mutants in chemostats. Genetics 46, 105122.

KubitscheK, H. E. \& Bendigkeit, H. E. (1964). Mutation in continuous cultures. I. Dependence of mutational response upon growth-limiting factors. Mutation Research 1, 113-120.

Miyoshi, T., Iseki, M., Konomi, T. \& IMANaKa, H. (1980). Biosynthesis of bicyclomycin. I. Appearance of aerial mycelia negative strains $\left(\mathrm{am}^{-}\right)$. Journal of Antibiotics 33, 480-487.

Okanishi, M. \& Umezawa, H. (1978). Plasmids involved in antibiotic production in streptomycetes. In Genetics of the Actinomycetales, pp. 19-38. Edited by E. Freerksen, I. Tarnok \& J. H. Thumin. Stuttgart \& New York: Gustav Fischer Verlag.

Omura, S., IKeda, H. \& Kitao, C. (1979). The detection of a plasmid in Streptomyces ambofaciens KA-1028 and its possible involvement in spiramycin production. Journal of Antibiotics 32, 10581060.

Perlman, D., Greenfield, R. B. \& O'Brien, E. (1954). Degeneration of a Streptomyces griseus mutant on repeated transfer. Applied Microbiology 2, 199-202. 
Reusser, F. (1961). Continuous fermentation of novobiocin. Applied Microbiology 9, 366-370.

Reusser, F., Koepsell, H. J. \& Savage, G. M. (1961). Degeneration of Streptomyces niveus with repeated transfers. Applied Microbiology 9, 342345.

Riesenberg, D. \& Bergter, F. (1979). Dependence of macromolecular composition and morphology of Streptomyces hygroscopicus on specific growth rate. Zeitschrift für allgemeine Mikrobiologie 19, 415430.

Sala, F. \& Westlake, D. W. S. (1966). Strain degeneration during continuous culture of a chloramphenicol-producing Streptomyces venezuelae. Canadian Journal of Microbiology 12, 817-829.

Salekh, S., Agre, N. S. \& KalakoutskiI, L. V. (1978). Production of nondifferentiated Streptomyces roseoflavus variants under submerged cultivation conditions. Mikrobiologiya 47, 226-229. (in Russian)
SALEKH, S., AgRE, N. S. \& KalaKoutSKII, L. V. (1979). Dynamics of accumulation of nondifferentiated variants in submerged cultures of Streptomyces roseoflavus var. roseofungini. Mikrobiologiya 48, 705-710. (in Russian)

SHU, P. (1966). Development of a cross-flow fermentation process with special reference to chlortetracycline production. Biotechnology and Bioengineering 8, 353-369.

Sikyta, B., Slezak, J. \& Herold, M. (1961). Growth of Streptomyces aureofaciens in continuous culture. Applied Microbiology 9, 233-238.

Williams, A. M. \& McCoy, E. (1953). Degeneration and regeneration of Streptomyces griseus. Applied Microbiology 1, 307-313.

Yagisawa, M., Huang, T.-S. R. \& Davies, J. E. (1978). Possible involvement of plasmids in biosynthesis of neomycin. Journal of Antibiotics 31, 809-813. 